\title{
Severidade da mancha anelar do mamoeiro em diferentes genótipos do grupo solo introduzidos em Cuba
}

\author{
Severity of papaya ringspot in different genotypes of the Solo group \\ introduced in Cuba
}

\author{
Douglas Rodríguez ${ }^{* 1,2}$, Yoel Tornet ${ }^{1}$, Maruchi Alonso ${ }^{1}$, Lázaro Valero ${ }^{1}$, Inés Peña ${ }^{1}$, \\ Antonia R. Figueira ${ }^{2}$ e Roberto $\operatorname{Ramos}^{3}$ \\ ${ }^{1}$ Instituto de Investigaciones en Fruticultura Tropical. Ave 7 ma entre 30 y 32. Miramar - Playa - Habana - Cuba. \\ ${ }^{2}$ Departamento de Fitopatologia,Universidade Federal de Lavras - UFLA, 37200-000; Lavras -MG - Brasil. \\ ${ }^{3}$ Empresa Nacional Productora y Comercializadora de Semillas Varias, Ministerio de la Agricultura, Ave. \\ Independencia esquina Conill. Plaza de la Revolución - Habana - Cuba.
}

\begin{abstract}
The severity of Papaya ring-spot virus (PRSV-P) induced symptoms was evaluated in five papaya's genotypes from the Solo group introduced in Cuba. Under field conditions different organs of plants were samples by grading from 1 to 5. Additional, evaluations regarding incubation period, number of infected plants and disease intensity were evaluated under the greenhouse conditions. The intensity of symptoms varies according to experimental conditions. In the fields conditions 'Sunset', 'Baixinho de Santa Amalia' and 'Golden' showed most intensities symptoms, while the rest behaved as moderate. Under greenhouse conditions 'BH-65' and 'Sunset' developed strong symptoms, 'Golden' and 'Baixinho de Santa Amalia' were intermediate and 'Sunrise Solo' was the less affected. 'Sunset', 'Sunrise Solo' and 'Golden' showed the most severe affectations in the fruits. In the fields less severe symptoms were developed in the leaves than those in other parts of the plant, and under the greenhouse conditions. These are the firsts results obtained in Cuba about this genotypes from the Solo group vs PRSV-P, revealing important results for the genetic breeding programs and varieties diversifications studies of this fruit.
\end{abstract}

Key-words: Carica papaya, Papaya ringspot virus, symptoms, intensity

\section{INTRODUÇÃO}

O mamoeiro (Carica papaya L.) é uma das fruteiras mais importantes e amplamente distribuídas nos países tropicais e subtropicais. $\mathrm{O}$ mamão resulta de grande importância devido ao seu elevado valor nutritivo e excelente sabor, sendo muito cotada tanto para o mercado nacional quanto para a exportação de fruta "in natura" ou produtos industrializados (Alonso et al., 2009b; Serrano e Cattaneo, 2010). Dentre os fatores que afetam a produção e comercialização dos frutos em nível mundial está a doença conhecida como mancha anelar, considerada a maior limitante desta cultura na maioria dos países. Esta doença é causada pelo Papaya ringspot virus (PRSV-P), que pode provocar perdas na produção que oscilam entre $5 \%$ e $100 \%$, dependendo da idade na qual o pomar é infectado (Purcifull et al., 1984).
O desenvolvimento da doença se caracteriza pelo aparecimento de mosaico, mosqueado e distorção das folhas mais jovens que chegam a tomar estrutura filiforme. Nos frutos se observam anéis concêntricos ou semicírculos de cor verde oliva, enquanto os pecíolos e o caule mostram manchas alargadas de cor escuro e aspecto oleoso. As plantas atacadas pelo PRSV-P produzem poucos frutos, de pequeno tamanho e de inferior qualidade em aroma, sabor, coloração e consistência (Purcifull et al., 1984). PRSV-P pertence à família Potyviridae, gênero Potyvirus e é transmitido de forma não persistente por mais de 20 espécies de afídeos (Martins e Ventura, 2007; Kalleshwaraswamy, 2008) e mecanicamente, infectando plantas das famílias Caricaceae, Chenopodiaceae e Cucurbitaceae (González et al., 2002). O comportamento da doença é afetado por

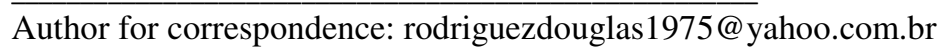


diversos fatores, entre eles, o genótipo do hospedeiro, a severidade das estirpes virais, as condições climáticas, a presença de vetores e as culturas associadas.

As estratégias de controle visam o manejo integrado, que consiste em intercalar o cultivo com culturas que constituam barreiras aos afídeos, a bioproteção com cepas atenuadas de PRSV, a supressão de plantas doentes e uso de variedades melhoradas geneticamente que sejam tolerantes ou resistentes à doença, entre outras medidas (Kung et al., 2009; Srivastava et al., 2009; Fermin et al., 2010).

Em Cuba estão sendo realizados diferentes estudos sobre o comportamento agro-produtivo de cultivares de mamoeiro (Alonso et al., 2009b; Méndez et al., 2010). No entanto, os estudos de susceptibilidade viral são mais escassos (Fariñas et al., 1983). Os resultados obtidos em vários desses trabalhos indicam que os cultivares avaliados manifestam alta susceptibilidade a doenças virais e, às vezes, baixos níveis de produção por planta. Uma forma de solucionar este problema é contar com um banco genético procedente de materiais locais e introduzidos do exterior, que permitam determinar e caracterizar a medida da variabilidade genética, e sugerir o melhor método de melhoramento para a cultura (Alonso et al, 2009a). Além disso, permitirá selecionar e obter genótipos promissores tolerantes a doenças e com características morfo-agronômicas favoráveis. Assim, o presente trabalho teve como objetivo avaliar o grau de severidade da mancha anelar em cinco genótipos de mamoeiro do grupo solo introduzidos em Cuba.

\section{MATERIAIS E MÉTODOS \\ Estudo em condições de campo}

$\mathrm{O}$ estudo foi desenvolvido em duas áreas experimentais da "Unidad Científico Tecnológica de Base" (UCTB), situada no município de Jagüey Grande, na província de Matanzas e pertencente ao "Instituto de Investigaciones en Fruticultura Tropical" (IIFT). A região esta situada entre os $22^{\circ}$ $30^{\prime}$ e $22^{\circ} 50^{\prime}$ de latitude norte e os $81^{\circ} 35^{\prime}$ e $81^{\circ}$ $51^{\prime}$ 'de latitude oeste, numa altitude entre os 3 e 25 msnm.

O clima dessa região durante o ensaio caracterizou-se por uma temperatura média de $24^{\circ} \mathrm{C}$, variando de $14,4^{\circ} \mathrm{C}$ a $33,4^{\circ} \mathrm{C}$. A precipitação média foi de $1.494,2 \mathrm{~mm}$ e a umidade relativa média superior a 80\% (Aranguren, 2009).
Durante oito meses foram avaliados os seguintes genótipos de mamoeiro do grupo Solo, introduzidos no Banco de Germoplasma da espécie: 'Baixinho de Santa Amalia', 'Sunset', 'Sunrise Solo', 'Golden' e 'BH-65', provenientes das Ilhas Canárias e do Brasil.

Para isso, semearam-se duas plantações formadas por estes cultivares em um desenho de blocos ao acaso, com três repetições, e 10 plantas por repetição, com uma distância de $2,0 \mathrm{~m}$ entre as plantas e 3,0 m entre as fileiras. Mensalmente foi amostrado o total de plantas de cada genótipo. Avaliou-se a presença de sintomas típicos da doença na haste, pecíolos, folhas e frutos, de acordo com o descrito por Purcifull et al. (1984) e Peña (2008). Para isso, elaborou-se a seguinte escala de notas: Nota 0: Ausência de sintomas. Nota 1: sintoma não bem definido. Nota 2: Sintoma evidente, mas pontual no órgão (folhas, haste, pecíolos ou frutos). Nota 3: Sintoma que atinge até $50 \%$ do órgão afetado (folhas, haste, pecíolos ou frutos) e não esta generalizado em toda a planta. Nota 4: Sintoma severo, mas que só afeta até $75 \%$ dos órgãos (folhas, haste, pecíolos ou frutos). Nota 5: Sintoma severo e generalizado em toda a planta.

Com os dados obtidos determinou-se o grau de severidade por órgão e a proporção de plantas afetadas no tempo para cada genótipo. Considerou-se que uma planta estava doente quando atingiu a nota 2 na escala utilizada. Com os resultados de proporção de plantas doentes foram elaboradas as curvas de progresso da doença (CPD), e a partir delas se determinou o inóculo inicial $\left(\mathrm{Y}_{0}\right)$, o inóculo final $\left(\mathrm{Y}_{\mathrm{f}}\right)$ e a área abaixo da curva de progresso da doença (AACPD), seguindo a fórmula AACPD $=\Sigma\left[\left(\mathrm{Y}_{1}+\mathrm{Y}_{2}\right) / 2 *\left(\mathrm{~T}_{2}-\mathrm{T}_{1}\right)\right]$, onde $\mathrm{Y}$ é a proporção de plantas doentes e $\mathrm{T}$, o tempo de avaliação (Campbell and Madden, 1990).

Para a análise dos dados comprovou-se a normalidade e homogeneidade da variância. Posteriormente, na análise de variância, as comparações entre as médias foram realizadas mediante o teste de Tukey $(\mathrm{p} \leq 0.05)$. Todas as análises foram realizadas utilizando o programa Statistica Ver. 6.0 (Statsoft, Tulsa, AZ, USA).

\section{Estudo em condições de casa de vegetação}

A intensidade dos sintomas nos genótipos estudados foi avaliada mediante a inoculação de plântulas de 30 dias de idade. Para isso, as plantas foram mantidas em sacos plásticos de um litro de capacidade com um substrato a base de zeólito, 
matéria orgânica e solo, em uma proporção 1:1:2 e mantidas em condições de casa de vegetação a temperatura ambiente.

A inoculação mecânica (Nascimento et al., 2011) se realizou aos 30 dias de semeadas, com o isolado CMT-J1, procedente de uma planta de mamoeiro cv. Maradol Roja pertencente à área urbana do município Jagüey Grande, que mostrava sintomas severos de mosaico e distorção foliar, assim como manchas de aspecto oleoso em pecíolos e frutos. A presença de PRSV-P foi confirmada previamente mediante Transcrição Reversa seguida de Reação em Cadeia da Polimerase (RT-PCR) com primers específicos da capa protéica viral, seguindo a metodologia usada por Chin et al. (2007). Inocularam-se 15 plantas por cada genótipo, mais 10 como controles negativos sem inocular. As plantas foram observadas a cada cinco dias, durante dois meses, em busca de sintomas típicos da doença (Purcifull et al., 1984, Peña, 2008).

Trinta dias após a inoculação confirmou-se a infecção pelo PRSV-P através da técnica PTAELISA (Plate Trapped Antigen - Enzyme Linked Inmunosorbent Assay), seguindo a metodologia de Peña et al. (2010), utilizando um antissoro policlonal.

\section{RESULTADOS}

\section{Sintomatologia observada}

Os sintomas observados coincidem com os descritos para a mancha anelar por outros autores (Purcifull et al., 1984; Espino de Paz et al., 1999; Ventura et al., 2004; Peña, 2008). Além disso, deve ser destacado o fato que durante o tempo avaliado não foram observados sintomas severos de distorção foliar descritos por Purcifull et al. (1984); e que têm sido observados em cultivares suscetíveis sob condições de campo por Bau et al. (2004).

\section{Proporção de plantas doentes}

Tabela 1. Inóculo inicial $\left(\mathrm{Y}_{0}\right)$, inóculo final $\left(\mathrm{Y}_{\mathrm{f}}\right)$ e área abaixo da curva de progresso da doença (AACPD) para cinco genótipos do grupo Solo sob condições de campo em Cuba.

\begin{tabular}{cccc}
\hline Genótipo & $\mathbf{Y}_{\mathbf{0}}$ & $\mathbf{Y}_{\mathbf{f}}$ & AACPD \\
\hline B.Sta Amalia & 0,07 & 0,72 & $1.9102 \mathrm{~b}^{*}$ \\
Sunset & 0,06 & 0,75 & $2.0583 \mathrm{~b}$ \\
Sunrise Solo & 0,00 & 1,00 & $4.5000 \mathrm{a}$ \\
Golden & 0,03 & 0,76 & $1.8926 \mathrm{bc}$ \\
BH-65 & 0,00 & 1,00 & $1.6000 \mathrm{c}$ \\
\hline
\end{tabular}

*letras iguais não diferem entre si pelo Teste de Tukey $(\mathrm{p} \leq 0,05)$.

Observou-se um aumento geral do número de plantas afetadas pela mancha anelar em todos os genótipos avaliados (Figura 1 e Tabela 1). Os a primeira avaliação (MAPA). Nesse momento 'Sunrise Solo' e 'BH-65' não mostraram plantas sintomáticas, enquanto que nos demais genótipos observaram-se plantas doentes em baixas proporções. Aos 2 MAPA, 'Sunrise Solo' mostrou um aumento até $100 \%$ das plantas doentes entanto 'BH-65' atingiu este valor só aos 6 MAPA. Os demais genótipos mostraram aumentos menos acelerados de plantas afetadas e proporções finais de 0,72 ('Baixinho de Santa Amalia'), 0,75 ('Sunset') e 0,76 ('Golden').

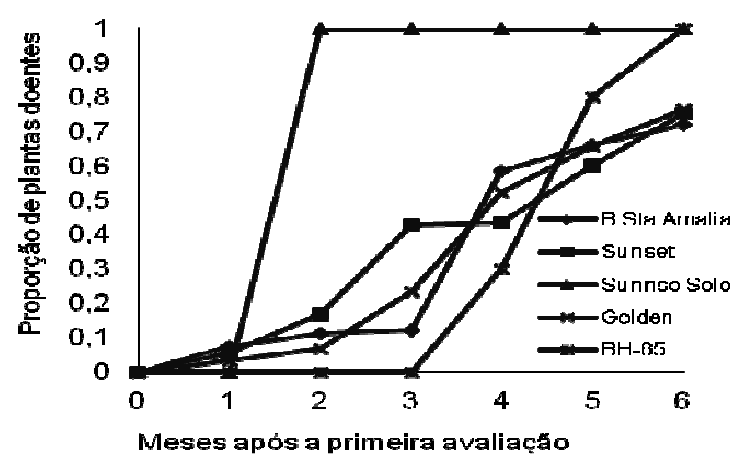

Figura 1- Progresso temporal da proporção de plantas afetadas pela mancha anelar (PRSV-P) em cinco genótipos de mamoeiro do grupo Solo introduzidos em Cuba, a partir dos três meses após o plantio. (4.500), que foi superior à obtida para 'Sunset'
(2.058), 'Baixinho de Santa Amalia' (1.910) e
'Golden' (1.893). Entanto que 'BH-65' apresentou
o menores valor com 1.600 , indicando menor
progresso da mancha anelar para esse genótipo. (4.500), que foi superior à obtida para 'Sunset'
'G.058), 'Baixinho de Santa Amalia' (1.910) e
o menores valor com 1.600 , indicando menor
progresso da mancha anelar para esse genótipo. (4.500), que foi superior à obtida para 'Sunset'
(2.058), 'Baixinho de Santa Amalia' (1.910) e
'Golden' (1.893). Entanto que 'BH-65' apresentou
o menores valor com 1.600, indicando menor
progresso da mancha anelar para esse genótipo. (4.500), que foi superior à obtida para 'Sunset'
(2.058), 'Baixinho de Santa Amalia' (1.910) e
'Golden' (1.893). Entanto que 'BH-65' apresentou
o menores valor com 1.600, indicando menor
progresso da mancha anelar para esse genótipo. (4.500), que foi superior à obtida para 'Sunset'
(2.058), 'Baixinho de Santa Amalia' (1.910) e
'Golden' (1.893). Entanto que 'BH-65' apresentou
o menores valor com 1.600, indicando menor
progresso da mancha anelar para esse genótipo.
A maior AACPD foi obtida para 'Sunrise Solo' 
Intensidade de sintomas na haste

Desde a primeira avaliação foram observadas manchas com aspecto oleoso nas hastes de Baixinho de Santa Amalia', 'Sunset', 'Sunrise Solo' e 'Golden', com uma intensidade baixa que oscilou entre 0,9 e 1,4 , sem diferenças significativas $(p \leq 0,05)$ entre eles (Dados não amostrados). Não entanto, 'BH-65', mostrou estas manchas a partir dos 3 MAPA. Com o passar do tempo, existiu um aumento geral da intensidade desses sintomas, observando-se ao final do período avaliado (Tabela 2) diferenças estatísticas $(p \leq 0,05)$ entre os genótipos. Os mais afetados foram 'Sunset' $(4,83)$ e 'Golden' $(4,26)$, sendo, por sua vez, 'Golden', similar aos menos afetados 'Baixinho de Santa Amalia' $(4,20)$, 'BH-65' $(3,96)$ e 'Sunrise Solo’' $(3,91)$.

Tabela 2. Intensidade de sintomas das manchas anelar em hastes, pecíolos e folhas de genótipos de mamoeiro do grupo Solo introduzidos em Cuba aos 11 meses após o plantio.

\begin{tabular}{lllll}
\hline Genótipo & Hastes & Pecíolos & Folhas & Frutos \\
\hline B. Sta. Amalia & $4,20 \mathrm{~b}^{*}$ & $5,0 \mathrm{a}$ & $3,2 \mathrm{~ns}$ & $1,8 \mathrm{~b}$ \\
Sunset & $4,83 \mathrm{a}$ & $4,8 \mathrm{ab}$ & $3,4 \mathrm{~ns}$ & $3,5 \mathrm{a}$ \\
Sunrise Solo & $3,91 \mathrm{~b}$ & $4,5 \mathrm{c}$ & $3,2 \mathrm{~ns}$ & $4,0 \mathrm{a}$ \\
Golden & $4,26 \mathrm{ab}$ & $4,4 \mathrm{c}$ & $3,0 \mathrm{~ns}$ & $3,5 \mathrm{a}$ \\
BH-65 & $3,96 \mathrm{~b}$ & $4,6 \mathrm{bc}$ & $2.6 \mathrm{~ns}$ & $2,2 \mathrm{~b}$ \\
\hline CV $(\%)$ & 4,23 & 2,32 & 9,45 & 12,88 \\
ES & $0,018^{*}$ & $0,011^{*}$ & 0,04 & $0,05^{*}$ \\
\hline
\end{tabular}

*letras iguais não diferem entre si pelo Teste de Tukey $(\mathrm{p} \leq 0,05)$.

\section{Intensidade de sintomas em pecíolos}

Quando foi analisada a intensidade dos sintomas em pecíolos, observou-se um aumento geral com o passar do tempo. Na primeira avaliação, todos os genótipos mantiveram um comportamento similar estatisticamente $\quad(\mathrm{p} \leq 0,05) \quad($ Dados não apresentados). Ao final do período avaliado (Tabela 2) foram observados três grupos estatisticamente diferentes. Os sintomas mais severos corresponderam a 'Baixinho de Santa Amalia' (5,0) e 'Sunset' (4,8). 'BH-65' mostrou sintomas intermediários $(4,6)$, que foram similares à anterior e aos menos severos observados em 'Sunrise Solo' $(4,5)$ e 'Golden' $(4,4)$. No entanto, deve ser destacado o fato que todos mantiveram uma intensidade superior a 4 na escala utilizada, fato que sugere o possível valor diagnóstico desse sintoma sob condições de campo.

\section{Intensidade de sintomas em folhas}

Desde a primeira avaliação foram observados sintomas de mosaico e mosqueado foliar em todos os genótipos, mas com intensidades baixas em todos os casos e sem diferenças significativas $(p \leq 0,05)$ entre eles (Dados não apresentados). Esta tendência manteve-se durante todo o período avaliado já que aos 11 MAPA todos os genótipos mostraram intensidades entre 2,6 e 3,4 , sem diferenças significativas (Tabela 2).
A menor intensidade de sintomas observada nas folhas quando comparada com hastes e pecíolos, difere do obtido por Purcifull et al. (1984), que descrevem sintomas mais severos de estruturas filiformes e deterioração total das folhas em plantas infectadas pelo PRSV-P. Estas diferenças poderiam ser dadas pela influência de diversos fatores, como a ausência de condições climáticas que favoreçam a intensificação dos sintomas foliares, a não infecção por raças de PRSV-P que provoquem sintomas foliares intensos, ou poderia ser que esses sintomas requeressem um período de infecção maior para poder se desenvolver.

\section{Intensidade de sintomas em frutos}

Durante as primeiras avaliações a maioria das plantas estava fora do período de frutificação e os frutos que haviam em algumas plantas eram muito pequenos para uma avaliação acertada. Ao final do período de avaliação, foram vistas diferenças significativas na intensidade de sintomas em frutos entre os genótipos analisados (Tabela 2). 'Sunrise Solo', 'Sunset' e 'Golden' apresentaram sintomas mais severos que 'BH-65' e 'Baixinho de Santa Amalia'. No caso dos genótipos com sintomas mais severos em frutos, estes podem chegar a afetar sua qualidade exportável, fato esse que o limitaria ao mercado interno e à indústria. 
Estudo sob condições de casa de vegetação

Todas as plantas inoculadas que mostraram sintomas típicos do PRSV-P foram positivas ao PTA-ELISA, enquanto que as assintomáticas e as testemunhas sadias foram negativas (Tabela 3). A maioria dos genótipos começaram a expressar sintomas da doença a partir dos 10 dias posteriores à inoculação, exceto ‘Sunset’ e 'Sunrise Solo’, que demoraram entre 15 e 20 dias, respectivamente. A extensão do período de incubação foi variável nos diferentes genótipos, sendo de até 20 dias para 'Golden', e até 25 e 30 dias para 'Baixinho de Santa Amalia' e 'BH-65', respectivamente, atingindo este último $100 \%$ de plantas com sintomas para esse período.

Tabela 3. Comportamento de diferentes parâmetros em plântulas de cinco genótipos de mamoeiro do grupo Solo inoculados com PRSV-P sob condições de casa de vegetação.

\begin{tabular}{cccccccc}
\hline Genótipo & P I & PS & P & \multicolumn{3}{c}{ Sintomas Foliares } & Sintomas \\
(dias) & $(\boldsymbol{\%})$ & $(\boldsymbol{\%})$ & Mosaico & Mosqueado & Distorção & em haste \\
\hline 'Sunrise Solo' & 20 & 10 & 10 & ++ & ++ & - & - \\
'B. S. Amalia' & $10-25$ & 70 & 70 & + & + & ++ & - \\
'Golden' & $10-20$ & 40 & 40 & ++ & +++ & + & + \\
'BH-65' & $10-30$ & 85 & 85 & +++ & +++ & +++ & +++ \\
'Sunset' & $15-25$ & 100 & 100 & ++ & ++ & +++ & +++ \\
\hline
\end{tabular}

Legenda: período de incubação (PI); plantas sintomáticas (PS); plantas positivas ao PTA-ELISA (P+); sintomas leves (+); sintomas moderados (++); sintomas severos (+++); ausência de sintomas (-).

Em relação à porcentagem de plantas infectadas (Tabela 3), destacou-se o genótipo 'Sunrise Solo' como o menos susceptível à inoculação mecânica pelo PRSV-P, com só $10 \%$ de plantas positivas. 'Golden' e 'Baixinho de Santa Amalia' tiveram um comportamento intermediário, com porcentagens respectivas de $40 \%$ e $70 \%$; enquanto que 'BH-65' e 'Sunset' foram as mais suscetíveis, com $85 \%$ e $100 \%$ das plantas infectadas, respectivamente. Esses resultados não coincidem com o observado em campo, fundamentalmente para 'Sunrise Solo' e 'Sunset', o que poderia ser explicado pelo possível comportamento diferencial das plantas à infecção do vírus pela via natural (transmissão não persistente por afídeos) e por via mecânica (inoculação com carbureto de silício 600 mesh). Neste sentido, Rodríguez et al. (2008) em um estudo sobre métodos de inoculação do PRSV$\mathrm{P}$, não obtiveram diferenças quanto à eficiência quando utilizaram a via mecânica em diferentes cultivares de mamoeiro.

Os sintomas foliares observados iniciaram com clorose das nervuras e posterior desenvolvimento de mosqueado, mosaico (consistente em bolhas de cor verde intensa) e distorção, que variaram em intensidade entre os diferentes genótipos. Neste sentido, observou-se que 'BH-65' desenvolveu os sintomas de mosqueado e mosaico de forma mais severa, enquanto que em 'Baixinho de Santa Amalia' foram mais leves (Tabela 3). Os demais genótipos mostraram esses sintomas de forma moderada.
A distorção foliar (Figuras 2C e 2D) foi severa em 'BH-65' e 'Sunset', moderada em 'Baixinho de Santa Amalia' e leve em 'Golden', enquanto que 'Sunrise Solo' não desenvolveu este sintoma. Por outra parte, as manchas de aspecto oleoso em hastes, foram observadas só em 'Golden' (leve), 'BH-65' (severa) e 'Sunset' (severa). Este último sintoma foi observado em plantas não inoculadas dos genótipos 'BH-65' e 'Golden'.

Os sintomas da doença expressados nos diferentes genótipos inoculados foram mais severos do que os observados em condições de campo. Esse fato pode dever-se à curta idade que tinham as plantas quando foram inoculadas e/ou ao isolado utilizado para a inoculação contenha uma raça severa de PRSV-P.

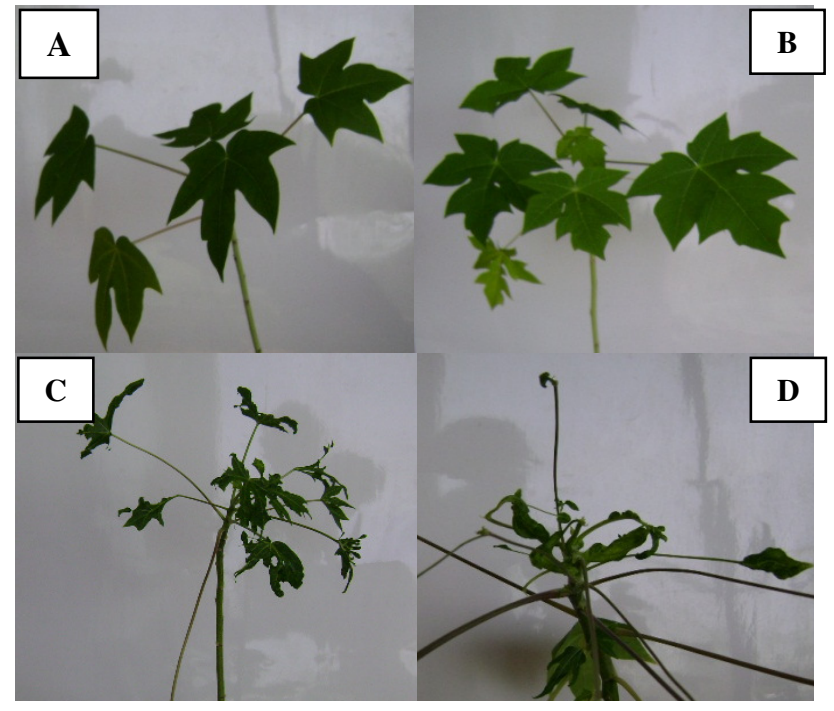


Figura 2 - Sintomas foliares de mancha anelar em plantas de mamoeiro após 30 dias da inoculação com PRSV-P. Controle sadio (A); sintomas leves de mosaico (B); sintomas moderados de bolhamento, engrossamento das nervuras e distorção foliar (C); sintomas severos de deformação foliar (D).

\section{DISCUSSÃO}

$\mathrm{O}$ rápido aumento de plantas com sintomas da doença observado neste estudo coincide com os trabalhos de incidência desta virose na cultura do mamoeiro realizados em regiões produtoras de vários países (Espino de Paz et al., 1999; Rivas Valencia et al., 2003; 2008). Contudo, o fato de identificar os primeiros sintomas a partir dos 3 meses após o plantio, difere do obtido em cultivares de mamoeiro suscetíveis ao PRSV-P em Taiwan (Bau et al., 2004) e México (Rivas Valencia et al., 2008), onde as primeiras plantas afetadas foram detectadas aos 29 e 47 dias após o plantio, respectivamente. Essas diferenças poderiam sugerir uma menor severidade da doença nos genótipos avaliados no nosso trabalho ou poderiam ser devidas à utilização da técnica ELISA que detecta a presença do PRSV-P nas plantas antes da aparição dos sintomas.

A rápida aparição dos sintomas em haste poderia constituir uma ferramenta valiosa na diagnose da mancha anelar em condições de campo. Porém, neste trabalho, foram observadas manchas oleosas nas hastes de plântulas dos genótipos 'Golden' e 'BH-65' que não foram inoculadas, o que denota sua pouca utilidade como diagnose específico da doença. Adicionalmente, Tomato spotted wilt virus (TSWV) e Cucumber mosaic virus (CMV), podem ocasionar sintomas parecidos aos provocados pelo PRSV-P nas hastes das plantas de mamoeiro (Gonsalves and Trujillo, 1986). Estas observações sugerem que este sintoma não deve constituir sozinho um elemento para diagnosticar a doença no campo, sendo que deve estar acompanhado de outros sintomas típicos de PRSV-P em frutos e pecíolos, embora em Cuba, TSWV seja quarentenário (MINAGRI, 2000) e CMV não tem sido detectado em mamoeiro.

A aparição antecipada de sintomas e de maior intensidade em pecíolos e hastes em relação aos foliares coincide com as observações de Gonsalves (1998), que atesta que as manchas oleosas em forma de anéis podem aparecer em frutos e flores. Mesmo assim, esses sintomas podem ser observados, inclusive, sem existir nenhuma sintomatologia nas folhas. Adicionalmente, os sintomas foliares em campo são menos específicos da doença, já que podem assemelhar-se aos provocados por outras doenças virais, bacterianas e fúngicas, entre outras desordens (Ventura et al., 2004; Peña, 2008).

Com relação aos sintomas observados em frutos, pode-se esperar que em períodos mais avançados da doença apareçam outros sintomas como frutos de pequeno tamanho e deformados (Ventura et al., 2004; Peña, 2008). Apesar disso, recomenda-se fazer análise de qualidade dos frutos desses genótipos, com o objetivo de identificar e quantificar os danos que possam existir em aroma, sabor e composição.

Os anéis concêntricos em frutos constituem o sintoma mais característico da doença em mamoeiro. No entanto, outros vírus (TSWV e Papaya lethal yelowing virus - PLYV) podem provocar sintomas parecidos (Peña, 2008) os quais poderiam ser confundidos com os do PRSV-P.

Os períodos de incubação observados quando se inocularam plantas em condições de casa de vegetação coincidem com os observados por Bau et al. (2004), que obtiveram plantas sintomáticas entre 20 e 30 dias posteriores à inoculação, embora períodos de incubação de até 43 dias tenham sido observados por Cabrera et al. (2008) em plantas de mamoeiro 'Maradol Roja' e de até sete semanas por Bau et al. (2003) em plantas não melhoradas geneticamente inoculadas e mantidas sob condições de campo. Estas diferenças poderiam sugerir uma maior suscetibilidade à inoculação mecânica com esse isolado de PRSV-P de alguns genótipos avaliados neste trabalho.

De maneira geral, os sintomas observados nas plantas inoculadas coincidem com os registrados na literatura cubana para esta doença (Fariñas and Peche, 1983; Peña, 2008) e com os observados em estudos de PRSV-P inoculados em plântulas de mamoeiro cv. Maradol Roja por Cabrera et al. (2008). Além disso, coincidem também com a sintomatologia observada por Bau et al. (2003) em ensaios de campo em Taiwan.

Os resultados de severidade da mancha anelar nesses genótipos de mamoeiro do grupo Solo constituem os primeiros obtidos sob as condições de Cuba e coincidem com o observado por Espino de Paz et al. (1999), os quais detectaram sintomas severos produzidos pelo PRSV-P em alguns destes materiais e nas cultivares Known you $\mathrm{N}^{\mathrm{o}} .1$ (784) e Red Lady (786) procedentes de Taiwan. As diferenças observadas entre os genótipos do grupo Solo avaliados sob condições de casa de vegetação 
sugerem a sua possível utilidade para ensaios de caracterização biológica de isolamentos de PRSVP.

Alguns dos genótipos avaliados neste trabalho estão sendo estudados no Brasil com o objetivo de aumentar a produtividade de mamão (Martelleto et al., 2008; Souza et al., 2009). Isso denota a importância da sua inclusão nos programas de diversificação e melhoramento genético do mamoeiro em Cuba, que inclui, entre outros aspectos, a introdução e avaliação de espécies tolerantes ao PRSV-P. Estes resultados, unidos a outros estudos de produção e qualidade dos frutos (Alonso et al., 2009a, 2009b), permitem a seleção de genótipos promissores de mamoeiro para realizar cruzamentos entre espécies do gênero Carica e entre diferentes gêneros, com o objetivo de obter maior resistência ao vírus como uma alternativa ao manejo integrado desta cultura. Isso será revertido em uma maior produção de mamão no país, a diminuição da cultura monovarietal nesta espécie e potencializará o mercado da exportação e consumo "in natura".

\section{AGRADECIMENTOS}

À Empresa Nacional Productora y Comercializadora de Semillas Varias, do Ministério da Agricultura de Cuba pelo financiamento do projeto. Ao Prof. Dr. Jorge Alberto Marques Rezende, da Escola Superior de Agricultura Luiz de Queiroz da Universidade de São Paulo, Piracicaba, São Paulo, Brasil por ter cedido gentilmente o antissoro policlonal usado no PTA-ELISA. À Dra. Denise Moedim Balani e a MSc. Nara Edreira, pela correção do português.

\section{RESUMO}

Neste estudo foi avaliada a severidade de sintomas induzidos pelo Papaya ringspot virus (PRSV-P) em cinco genótipos de mamoeiro (Carica papaya L.) do grupo Solo introduzidos em Cuba. Sob condições de campo, amostraram-se diferentes órgãos das plantas, seguindo uma escala de 1 a 5. Em condições de casa de vegetação foram avaliados parâmetros como período de incubação, número de plantas infectadas e severidade da doença em plântulas inoculadas com o vírus. A intensidade dos sintomas variou com as condições experimentais. No campo, os sintomas foram mais severos em 'Sunset', 'Baixinho de Santa Amalia' e 'Golden', enquanto que nos demais observaram-se sintomas moderados. Em Casa de Vegetação, 'BH-65' e 'Sunset' desenvolveram sintomas mais severos, 'Golden' e 'Baixinho de Santa Amalia' intermediários; e 'Sunrise Solo' foi o menos afetado. 'Sunset', 'Sunrise
Solo' e 'Golden' mostraram os maiores danos em frutos. Os sintomas foliares em campo foram menos severos do que os desenvolvidos pelos demais órgãos das plantas (exceto os frutos), e que os observados em casa de vegetação. São os primeiros resultados obtidos em Cuba sobre genótipos do grupo Solo ante o PRSV$\mathrm{P}$, oferecendo resultados valiosos para os programas de diversificação de variedades e estudos de melhoramento genético dessa frutífera.

Palavras-chave: Carica papaya, Papaya ringspot virus, sintomas, intensidade

\section{REFERÊNCIAS}

Alonso, M.; Bautista, M.; Ortiz, M.; Quiroz, A.; Rohde, W.; Sánchez, L. F. (2009a), Caracterización de accesiones de papaya (Carica papaya L.) a través de marcadores AFLP en Cuba. Revista Colombiana de Biotecnología, 11: 31-39.

Alonso, M.; Tornet, Y.; Ramos, R.; Farrés, E.; Castro, J.; Pastor, M. C. (2009b), Establecimiento y evaluación de cultivares de papaya introducidos en Cuba. Revista CitriFrut, 26:27-33.

Aranguren, M. Pronósticos de madurez y otras especificaciones de calidad para el ordenamiento de la cosecha en los cítricos de Jagüey Grande, Tesis (Doctorado en Ciencias Agrícolas), Instituto Nacional de Ciencias Agrícolas, Habana, Cuba, 2009.

Bau, H. J.; Cheng, Y. H.; Yu, T. A.; Yang, J. S.; Liou, P. C.; Hsiao, C. H.; Lin, C.Y.; Yeh, S. D. (2004), Field evaluation of transgenic papaya lines carrying the coat protein gene of Papaya ringspot virus in Taiwan. Plant Diseases, 88:594-599.

Bau, H. J.; Cheng, Y. H.; Yu, T. A.; Yang, J. S.; Yeh, S. D. (2003), Broad-spectrum resistance to different geographic strains of Papaya ringspot virus in coat protein gene transgenic papaya. Phytopathology, 93: 112-120.

Cabrera, D.; Cruz, M.; González, J. E.; Hernández, R.; Portal, O. (2008), Diagnóstico y caracterización biológica de un aislado del Virus de la Mancha Anular de la Papaya (PRSV-P) procedente de Cienfuegos, Cuba. Revista Centro Agrícola, 35: 91-93.

Campbell, C. L. e Madden, L. W. (1990), Introduction to Plant Disease Epidemiology. New York, Wiley, USA: John Wiley \& Sons. 
Chin, M.; Rojas, Y.; Moret, J.; Fermin, G.; Tennant, P.; Gonsalves, D. (2007), Varying genetic diversity of Papaya ringspot virus isolates from two time-separated outbreaks in Jamaica and Venezuela. Archives of Virology, 152: 2101-2106.

Espino de Paz, A. I.; Rodríguez Pastor, M. C.; Marrero Ferrer, M.; de León Rodríguez, J. M. (1999), Estudio preliminar sobre la incidencia y distribución de virosis en papaya (Carica papaya L.) en la isla de Gran Canaria. Phytoma, 106: 3135 .

Fariñas, M. E.; Robbio, M.; González, M.; López, E. (1983), Comportamiento de una variedad de Fruta bomba (Carica papaya) procedente de São Tomé en condiciones de Cuba. I. Morfología y susceptibilidad viral. Ciencia Técnica en la Agricultura. Serie Cítricos y otros Frutales, 6: 2941.

Fermin, G.; Castro, L. T.; Tennat, P. F. (2010), $\mathrm{CP}$-transgenic and non-transgenic approaches for the control of papaya ringspot: current situation and challenges. Transgenic Plant J, 4: 1-15.

Gonsalves, D. e Trujillo, E. E. (1986) Tomato spotted wilt virus in papaya and detection of the virus by ELISA. Plant Diseases, 70: 501-505.

Gonsalves, D. (1998), Control of PRSV in papaya: A case study. Annual Review of Phytopathology, 36: $415-431$.

González, A.; Trujillo, G.; Vegas, A.; Garrido, M. J. (2002), Hospedantes de cepas del Virus de la mancha anillada de la lechosa en Venezuela. Fitopatología Venezolana, 15: 7-12.

Kalleshwaraswamy, C. M. e Krishna Kumar, N. K. (2008), Transmission efficiency of Papaya ringspot virus by three aphid species. Phytopathology, 98: 541-546.

Kung, Y. J.; Bau, H. J.; Wu, Y. L.; Huang, C. H.; Chen, T. M.; Yeh, S. D. (2009), Generation of transgenic papaya with double resistance to Papaya ringspot virus and Papaya leaf-distortion mosaic virus. Phytopathology, 99: 1312-1320.

Martelleto, L. A. P.; Ribeiro, R. L.D.; SudoMartelleto, M.; Vasconcellos, M.A.S.; Marin, S. L. D.; Pereira, M. B. (2008), Cultivo orgânico do mamoeiro 'Baixinho de Santa Amália' em diferentes ambientes de proteção. Revista Brasileira de Fruticultura, 30: 662-666.

Martins, D. S. e Ventura, J. Á. (2007), Vetores de doenças do mamoeiro: monitoramento e controle. Papaya Brasil: mercado e inovações tecnológicas para o mamão. Vitória: Incaper, 115-128p.

Méndez, Y.; Rosabal, R.; Alonso, M.; Fajardo, M.; Farrés, E.; Ramos, R. Establecimiento de nuevos cultivares de papaya (Carica papaya L.) en la región oriental de Cuba. (2010), In: III Simposio Internacional de Fruticultura Tropical y Subtropical, Habana, Cuba. Anais. Fruticultura 2010.

MINAGRI. (2000), Vigilancia Fitosanitaria: Plagas Cuarentenadas. 1. Ed. Centro Nacional de Sanidad Vegetal, MINAGRI, 18p.

Nascimento, L. B. S.; Figueira, A. R.; Santos, G. R.; Aguiar, R. W, S.; Maluf, W. R.; Oiveira, G. I. S. (2011), Identificação molecular de espécies de vírus e reação fenotípica de famílias de melancia a um isolado do vírus da mancha anelar do mamoeiro, estirpe melancia (Papaya ringspot virus - strain watermelon - PRSV-W). Journal of Biotechnology and Biodiversity, 2: 2229.

Peña, I. (2008), Enfermedades virales en el cultivo del papayo (Carica papaya L.). Revista CitriFrut, 25: 13-23.

Peña, I.; López, D.; Leyva, J.; Batista, L. Estandarización de técnicas inmunoenzimáticas para el diagnóstico del Virus de la mancha anular del papayo. (2010), In: III Simposio Internacional de Fruticultura Tropical y Subtropical, Habana, Cuba. Anais. Fruticultura 2010.

Purcifull, D. E.; Edwardson, J. R.; Hiebert, E.; Gonsalves, D. (1984), Papaya ringspot virus. CMI/AAB. Description of plant viruses, 292, 8p.

Rivas-Valencia, P.; Mora-Aguilera, G.; TélizOrtiz, D.; Mora-Aguilera, A. (2008), Evaluation of plant barriers in an integrated management of papaya ringspot in Michoacan, Mexico. Summa Phytopathologica, 34: 307-312. 
Rivas-Valencia, P.; Mora-Aguilera, G.; TélizOrtiz, D.; Mora-Aguilera, A. (2003), Influencia de Variedades y Densidades de Plantación de Papayo (Carica papaya L.) Sobre las Epidemias de Mancha Anular. Revista Mexicana de Fitopatologia, 21: 94-102.

Rodríguez, D.; Pérez, R.; Peña, I.; López, D. Comparación de la efectividad en la transmisión mecánica del Virus de la mancha anular del papayo (PRSV-P), según el procedimiento empleado. (2008), In: VI Seminario Científico Internacional de Sanidad Vegetal, Habana, Cuba. Anais APS 2008.

Serrano, L. A. L. e Cattaneo, L. F. (2010), O cultivo do mamoeiro no Brasil. Revista Brasileira de Fruticultura, 32: 657-959.
Souza, M. S.; Azevedo, I. G.; Corrêa, S. F.; Silva, M. G.; Pereira, M. G.; Oliveira, J. G. (2009), Resposta da aplicação do 1-MCP em frutos de mamoeiro 'Golden' em diferentes estádios de maturação. Revista Brasileira de Fruticultura, 31:693-700.

Srivastava, A.; Trivedi, S.; Krishna, S. K.; Verma, H. N.; Prasad, V. (2009), Suppression of Papaya ringspot virus infection in Carica papaya with CAP-34, a systemic antiviral resistance inducing protein from Clerodendrum aculeatum. European Journal of Plant Pathology, 123: 241-246.

Ventura, J. A.; Costa, H.; Tatagiba, J. S. (2004), Papaya diseases and integrated control. In: Naqvi SAMH. Diseases of fruits and vegetables: diagnosis and management. 1. ed. London UK: Klumer Academic Publishers, 2, 201-268p. 